\title{
Philosophy of medicine in 2021
}

\author{
Jeremy R. Simon ${ }^{1} \cdot$ Maël Lemoine ${ }^{2}$ (D)
}

Published online: 27 February 2022

(ᄋ) The Author(s), under exclusive licence to Springer Nature B.V. 2022

This journal issue is a time capsule. Of course, all issues of this journal reflect work done at least a year or so in the past, but never has the time between producing the work and presenting it brought such a change to the world in general and philosophy of medicine in particular. COVID-19 is surely not the first catastrophe to rearrange lives. Any of the Four Horsemen can do that. But it has been at least a century, stretching back to the last pandemic, since such a change has been felt so globally. Even World War II left much of the Southern Hemisphere relatively unscathed. COVID-19 is unique not just in its geographic spread, but in its impact on philosophy of medicine as well. Epidemiology, public health, medical research, and the information infrastructure of medicine are being stressed in ways that they have not been even in prior pandemics, and these stresses reveal gaps in our understanding of these tools that philosophy of medicine is now starting to grapple with. Future issues of this journal will undoubtedly bear the imprint of COVID-19.

However, as we said, this issue is a time capsule, coming from a few months before COVID-19 became visible on the horizon. As we have done several times in the past, we are pleased to present a special issue of Theoretical Medicine and Bioethics with a selection of papers from the 8th International Philosophy of Medicine Roundtable (IPMR), held in Paris in June 2019 and hosted by University of Paris I Panthéon-Sorbonne. As always, there were speakers from around the world, with keynote addresses by Phyllis Illari and Thomas Pradeau.

Even setting COVID-19 aside, the time since the preceding roundtable in Toronto in 2017 has been one of explosive growth in philosophy of medicine. Each year now seems to bring as many books in the field as used to appear in a decade. Just surveying the English literature since 2017, a certainly incomplete list includes works authored by or edited by Anjum, Copeland, and Rocca [1], Broadbent [2], Dammann [3], Dammann and Smart [4], Gadebusch Bondio, Spöring, and Gordon [5],

Jeremy R. Simon

js1115@columbia.edu

Maël Lemoine

mael.lemoine@u-bordeaux.fr

1 Department of Emergency Medicine, Columbia University, New York, NY, USA

2 University of Bordeaux, Bordeaux, France 
Gillies [6], Lalumera and Fanti [7], Louhiala [8], Méthot and Sholl [9], Parkkinen, Wallmann, Wilde, et al. [10], Plutynski [11], Schramme [12], Sholl and Rattan [13], Stegenga [14, 15], Thompson and Upshur [16], and Valles [17]. Books are also regularly being published in German, Spanish, and French (among other languages). Additionally, while it may be impolitic to mention in this setting, there is also a new online journal, Philosophy of Medicine (http://philmed.pitt.edu/philmed).

Unlike prior roundtable special issues, this issue is not exclusively dedicated to papers from IPMR. In addition to three papers presented at IPMR, we are rounding out the issue with a paper by de Boer and Kudina [18]. This paper was not presented at the roundtable but rather was accepted through the journal's usual submission and review process. Nonetheless, the journal's editors felt that it was thematically similar enough to include in this issue. The issue concludes with a review article by one of us (Jeremy Simon), discussing three recent important books on philosophy of medicine [19]. This essay, too, was selected by the journal's editors for inclusion based on its thematic consistency and not by the issue editors. Nor does it have its genesis in the preparation of this issue or IPMR. Those hungry for still more International Philosophy of Medicine Roundtable papers after finishing this issue can find one by Stefano Canali in International Journal of Environmental Research and Public Health [20], one by Anke Bueter in Philosophy of Science [21], and one by Insa Lawler and Georg Zimmermann in Topoi [22]. Others should be forthcoming as well.

Readers may notice that one of the papers in this issue was co-authored by one of the issue editors. This did not affect its acceptance. While the editors did initially review each submission, every paper was refereed by three independent readers and recommended by at least two of them. Needless to say, Jeremy Simon edited the paper by Tabb and Lemoine.

The issue begins with this paper [23]. Over the past decade or so, precision medicine has been introduced, in one form or another, to many medical fields. What precision medicine consists in is already a matter of discussion in philosophy of science [24-26], ethics [27], and social science [28, 29]. Does a closer look at specific medical fields support the view that precision is a general trend that will change medicine writ large, or does it suggest that precision medicine is and will be, at least for a long time, limited to such medical specialties as oncology? Katherine Tabb and Maël Lemoine propose a comparison of two fields in which there are claims that precision medicine has started a revolution: psychiatry and oncology. Beyond the obviously rhetorical aspects of these claims, the main question, they argue, revolves around the problem of what a biomarker is and the purposes it can serve. They propose a distinction between "mechanistic biomarkers," or biomarkers mechanistically associated with an identified locus of control of a disease that provides a potential target of intervention, and "statistical biomarkers," or biomarkers simply correlated with the signs and symptoms of a condition in a population. They also emphasize that in precision medicine, biomarkers are ideally used for theranostic purposes, that is, to choose treatment based on what the response to the treatment will be. Within this framework, Tabb and Lemoine observe that whereas in oncology some biomarkers are mechanistic and truly used for theranostic purposes, in psychiatry they are, at least in some cases, statistical and mainly used for taxonomic purposes. This 
suggests that psychiatry is not ready for precision medicine as of yet, if it is amenable to it at all. The general conclusion is that only some medical specialties, and not medicine in general, are likely to be transformed by precision medicine.

The second paper, by Antoine Dussault, considers the concept of harm as used in accounts of disease [30]. Initially designed inside the field of psychiatry to account for mental disorders only, Wakefield's harmful dysfunction analysis (HDA) has since been extended into a full-fledged account of all diseases. It is intended to mitigate the excesses of so-called naturalistic accounts of disease based only on the notion of dysfunction by appealing to a harm condition. In this way, the HDA presents a hybrid account of disease based on two necessary and jointly sufficient conditions: that the condition is dysfunctional and that it harms the bearer. As a general account of disease, and not just of mental disorders or of human diseases, the HDA should account for diseases in all living beings. Yet it is not easy to define what "harm" might mean for plants, fungi, or invertebrates, if not dysfunction itself. Dussault proposes that a strong candidate notion for applying the harm requirement to these organisms is the notion of interests, as used in environmental ethics. However, Dussault's analysis shows that even in this apparently convincing framework, it is unclear that the notion of harm can really be defined independently of the dysfunction component of the definition of disorder.

This paper is one of the few to focus on the harm component of the extended HDA. The case of nonsentient organisms may appear marginal to philosophers of medicine, yet it is crucially important to naturalism, as it is obvious that plants, microbes, and sponges have diseases too. A part of the debate on disease suffers from the implicit assumption that medicine is the science of disease and that philosophy of medicine deals with a medical concept. Dussault's paper should be read alongside recent work on the concept of disease by philosophers of biology Paul Griffiths and John Matthewson [31-33].

The next paper in this issue, by Bengt Autzen, considers the replication crisis [34]. This crisis arises from the apparently surprising state of affairs in which the findings of remarkably few positive clinical studies are able to be replicated by others. This low replicability seems to call into question the evidentiary value of published studies. Alexander Bird suggests that while the inability to replicate trials may be problematic, it should not be surprising [35]. He argues that since the prior probability that any hypothesis is true is so low, the fact that a positive study with a significance level as high as 0.05 should appear to support a hypothesis does not make the posterior probability of that hypothesis particularly high. Thus, it should not be considered surprising that the findings of that study cannot be replicated, since the hypothesis is likely false.

Autzen has two responses to Bird. The first is that although the average prior probability that a biomedical hypothesis is true may indeed be very low, the prior probability of a given study could be much higher, such that there may in fact be reason to believe the hypothesis when the study is positive. In support of this claim he cites John Ioannidis [36], who suggests that while the prior probability of what he calls "discovery-oriented exploratory research" hypotheses may be around 0.001 , the prior probability of meta-analyses is more likely between 0.25 and 0.66. Even randomized controlled trials have prior probabilities of 0.17 to 
0.5. These priors are high enough that a positive study could result in substantial posterior probability. Many of these hypotheses are therefore likely to be true, and should be replicable, and thus the base-rate does not explain the failure to replicate findings. Autzen's second point is that the replication crisis can likely be better explained by supplementing base-rate analyses with a consideration of the role that bias-in particular, selective reporting-plays in the number of false positives reported in the medical literature.

The final paper in this issue, which, as noted above, is not from IPMR, is by Bas de Boer and Olya Kudina [18]. In this paper, the authors use tools from philosophy of technology to expand the range of ethical and philosophical questions that people should be asking about the impact of new technologies on medicine, using machine learning as an example. They note that assessments of the ethical impact of new technologies on medicine primarily look at what they call "hard impacts." These are measurable effects that the new technology may have on ethically salient factors, such as the physical risks to patients or the rate of misdiagnosis. However, de Boer and Kudina call attention to the need to examine non-quantifiable "soft impacts"- that is, the ways in which new technologies do not merely change calculations, but change the whole calculus. For instance, a technology such as machine learning might change the extent to which doctors are morally responsible for the treatment decisions they make. Other technologies might alter our sense of what it is to be human and what the boundaries of the self are. The tools the authors use to bring out these soft impacts are drawn from the analytic approaches of technomoral change and technological mediation theory, each of which in its own way investigates how technologies not only fit into, but also reshape the world around them.

We hope that readers enjoy the papers in this issue and will join us for further International Philosophy of Medicine Roundtable events, both live and in print.

\section{References}

1. Anjum, Rani Lill, Samantha Copeland, and Elena Rocca (eds.). 2020. Rethinking causality, complexity and evidence for the unique patient: A CauseHealth resource for healthcare professionals and the clinical encounter. Cham: Springer.

2. Broadbent, Alex. 2019. Philosophy of medicine. New York: Oxford University Press.

3. Dammann, Olaf. 2020. Etiological explanations: Illness causation theory. Boca Raton, FL: CRC Press.

4. Dammann, Olaf, and Benjamin Smart. 2019. Causation in population health informatics and data science. Cham: Springer.

5. Gadebusch Bondio, Mariacarla, Francesco Spöring, and John-Stewart Gordon (eds.). 2017. Medical ethics, prediction, and prognosis: Interdisciplinary perspectives. New York: Routledge.

6. Gillies, Donald. 2019. Causality, probability, and medicine. London: Routledge.

7. Lalumera, Elisabetta, and Stefano Fanti (eds.). 2020. Philosophy of advanced medical imaging. Cham: Springer.

8. Louhiala, Pekka. 2020. Placebo effects: The meaning of care in medicine. Cham: Springer.

9. Méthot, Pierre-Olivier, and Jonathan Sholl (eds.). 2020. Vital norms: Canguilhem's The Normal and the Pathological in the twenty-first century. Paris: Hermann.

10. Parkkinen, Veli-Pekka, Christian Wallmann, Michael Wilde, Brendan Clarke, Phyllis Illari, Michael P. Kelly, Charles Norell, Federica Russo, Beth Shaw, and Jon Williamson. 2018. Evaluating evidence of mechanisms in medicine: Principles and procedures. Cham: Springer.

11. Plutynski, Anya. 2018. Explaining cancer: Finding order in disorder. New York: Oxford University Press. 
12. Schramme, Thomas. 2019. Theories of health justice: Just enough health. London: Rowman and Littlefield.

13. Sholl, Jonathan, and Suresh I.S. Rattan. 2019. Explaining health across the sciences. Cham: Springer.

14. Stegenga, Jacob. 2018. Care and cure: An introduction to philosophy of medicine. Chicago: University of Chicago Press.

15. Stegenga, Jacob. 2018. Medical nihilism. Oxford: Oxford University Press.

16. Thompson, R. Paul, and Ross E.G. Upshur. 2018. Philosophy of medicine: An introduction. New York: Routledge.

17. Valles, Sean A. 2018. Philosophy of population health: Philosophy for a new public health era. London: Routledge.

18. De Boer, Bas, and Olya Kudina. 2021. What is morally at stake when using algorithms to make medical diagnoses? Expanding the discussion beyond risks and harms. Theoretical Medicine and Bioethics 42. https://doi.org/10.1007/s11017-021-09553-0.

19. Simon, Jeremy R. 2021. Introducing philosophy of medicine: Three new books. Theoretical Medicine and Bioethics 42. https://doi.org/10.1007/s11017-021-09554-z.

20. Canali, Stefano. 2020. What is new about the exposome? Exploring scientific change in contemporary epidemiology. International Journal of Environmental Research and Public Health 17: 2879-2888.

21. Bueter, Anke. 2019. Epistemic injustice and psychiatric classification. Philosophy of Science 86: 1064-1074.

22. Lawler, Insa, and Georg Zimmermann. 2019. Misalignment between research hypotheses and statistical hypotheses-a threat to evidence-based medicine? Topoi 40: 307-318.

23. Tabb, Kathryn, and Maël. Lemoine. 2021. The prospects of precision psychiatry. Theoretical Medicine and Bioethics 42. https://doi.org/10.1007/s11017-022-09558-3.

24. Green, Sara, and Henrik Vogt. 2016. Personalizing medicine: Disease prevention in silico and in socio. Humana.Mente 30: 105-145.

25. Vogt, Henrik, Bjørn Hofmann, and Linn Getz. 2016. Personalized medicine: Evidence of normativity in its quantitative definition of health. Theoretical Medicine and Bioethics 37: 401-416.

26. Boniolo, Giovanni, and Marco J. Nathan (eds.). 2016. Philosophy of molecular medicine: Foundational issues in research and practice. New York: Routledge.

27. Juengst, Eric, Michelle L. McGowan, Jennifer R. Fishman, and Richard A. Settersten Jr. 2016. From "personalized" to "precision" medicine: The ethical and social implications of rhetorical reform in genomic medicine. Hastings Center Report 46(5): 21-33.

28. Pokorska-Bocci, Anna, Alison Stewart, Gurdeep S. Sagoo, Alison Hall, Mark Kroese, and Hilary Burton. 2014. "Personalized medicine": What's in a name? Personalized Medicine 11: 197-210.

29. Tutton, Richard. 2014. Genomics and the reimagining of personalized medicine. Surrey: Ashgate.

30. Dussault, Antoine C. 2021. Wakefield's harmful dysfunction analysis of disorder and the problem of defining harm to nonsentient organisms. Theoretical Medicine and Bioethics 42. https://doi.org/10. 1007/s11017-022-09559-2.

31. Griffiths, Paul E., and John Matthewson. 2016. Evolution, dysfunction, and disease: A reappraisal. British Journal for the Philosophy of Science 69: 301-327.

32. Matthewson, John, and Paul E. Griffiths. 2017. Biological criteria of disease: Four ways of going wrong. Journal of Medicine and Philosophy 42: 447-466.

33. Griffiths, Paul E., and John Matthewson. 2020. Diseases are not adaptations and neither are their causes. Biological Theory 15: 136-142.

34. Autzen, Bengt. 2021. Is the replication crisis a base-rate fallacy? Theoretical Medicine and Bioethics 42. https://doi.org/10.1007/s11017-022-09561-8.

35. Bird, Alexander. 2021. Understanding the replication crisis as a base rate fallacy. British Journal for the Philosophy of Science 72: 965-993.

36. Ioannidis, J.P.A. 2005. Why most published research findings are false. PLoS Medicine 2: 124. https:// doi.org/10.1371/journal.pmed.0020124.

Publisher's Note Springer Nature remains neutral with regard to jurisdictional claims in published maps and institutional affiliations. 